Original Research Article

\title{
A prospective study to compare the efficacy of tacrolimus vs cyclosporine in vernal keratoconjunctivitis in children in India
}

\author{
Priya Choudhary ${ }^{1 *}$, Satya Prakash Singh ${ }^{2}$, Rakesh Chandra Chaurasia ${ }^{3}$, Meenakshi Jindal ${ }^{4}$
}

${ }^{1}$ Department of Pharmacology, Muzaffarnagar Medical College Muzaffarnagar, Uttar Pradesh, India

${ }^{2}$ Department of Ophthalmology, ${ }^{3}$ Department of Pharmacology, Moti Lal Nehru Medical

College, Allahabad, Uttar Pradesh, India

${ }^{4}$ Department of Pharmacology, Muzaffarnagar Medical College Muzaffarnagar, Uttar Pradesh, India

Received: 22 March 2019

Revised: 05 April 2019

Accepted: 03 May 2019

\section{*Correspondence to:}

Dr. Priya Choudhary,

Email:

choudharypp@gmail.com

Copyright: (C) the author(s), publisher and licensee Medip Academy. This is an openaccess article distributed under the terms of the Creative Commons Attribution NonCommercial License, which permits unrestricted noncommercial use, distribution, and reproduction in any medium, provided the original work is properly cited.

\begin{abstract}
Background: Vernal keratoconjunctivitis (VKC) is a chronic allergic conjunctival disease. Immunomodulatory drugs like cyclosporine is being used for its treatment. Tacrolimus is another immunomodulator drug that can be used in VKC. This study was done to compare the efficacy of tacrolimus and cyclosporine in VKC.

Methods: This prospective study was conducted on 60 patients of either sex by dividing them into two groups. The first group was treated with cyclosporine $(0.05 \%)$ ophthalmic eye drop and second group with tacrolimus $(0.03 \%)$ ophthalmic ointment. Total five objective signs (hyperaemia, oedema, papillae, corneal involvement and tantra's dot) and five subjective symptoms (itching, tearing, foreign body sensation, discharge and photophobia) data was collected and tabulated for statistical analysis.

Results: Authors found TSSS in both groups decrease significantly ( $\mathrm{p}<0.05$ or $\mathrm{p}<0.01$ or $\mathrm{p}<0.001$ ) at all post periods as compared to respective predecessor periods except 4 weeks to 6 weeks in cyclosporine group and 6 weeks to 8 weeks in tacrolimus group. Similarly, for each period, on comparing the mean TSSS between the groups TSSS between the groups at all periods does not differed statistically though at final evaluation (mean change from baseline to 8 weeks), it improved $5.2 \%$ more in tacrolimus group $(83.7 \%)$ than cyclosporine group (78.5\%). Similarly, TOSS also decreased at all post periods except 4 weeks to 6 weeks, and 6 weeks to 8 weeks in cyclosporine group and 6 weeks to 8 weeks in tacrolimus group. Improvement in scores was $11.6 \%$ more in tacrolimus $(81.6 \%)$ than cyclosporine $(70.0 \%)$. Cyclosporine eye drops are associated with burning sensation and redness of eyes while transient ocular irritation was only observed side effect with tacrolimus.

Conclusions: The study found tacrolimus is clinically better drug for treatment of vernal keratoconjunctivitis than cyclosporine and is also cost effective.
\end{abstract}

Keywords: Tacrolimus, Cyclosporine, Vernal keratoconjunctivitis, Immunomodulatory

\section{INTRODUCTION}

Vernal keratoconjunctivitis (VKC) is a chronic condition that affects children and young adults. This condition appears before 10 years of age and lasts for 2 to 10 years, with spontaneous recovery during puberty. The diagnosis is essentially clinical. Symptoms include intense itching, tearing, mucous secretion and photophobia and conjuctival signs include hyperaemia, papillae and Horner Tantra's dot. ${ }^{1,2} \mathrm{VKC}$ is characterised by conjunctival in filterations 
with eosinophils, degranulated mast cells, basophils, plasma cells, lymphocytes and macrophages, conjuctival scrapings have yielded Th2 clones. ${ }^{3}$ Increased production of Th2 cytokines may contribute to tissue remodelling and papillary formation on tarsal conjunctiva. ${ }^{4}$

Drug therapy for allergic conjunctival disease often utilises topical and oral antiallergic agents or steroids. However, antiallergic agents often have insufficient efficacy and long-term patient management is usually required with this therapy..$^{5}$ The use of ocular steroids is associated with a serious increased risk of ocular hypertension, cataracts and/or glaucoma. ${ }^{6,7}$ Additionally, the risk of steroid-induced ocular hypertension is particularly high in children less than 10 years old and a cataract-induced visual acuity reduction during infancy or early childhood markedly affects a patient's quality of life. ${ }^{8}$

Immunomodulatory drugs like cyclosporine has been successfully used for treatment of moderate to severe vernal keratoconjunctivitis. ${ }^{9,10}$ There are studies suggesting use of tacrolimus another immunomodulatory drug in treatment of various eye conditions. However, there are fewer studies in which comparison of tacrolimus and cyclosporine treatment for $\mathrm{VKC}$ in terms of efficacy and safety is done and none of the study is done in Indian setup.

This study was conducted with the objectives of evaluating the efficacy of tacrolimus and its comparison with cyclosporine in the treatment of vernal keratoconjunctivitis (VKC). Safety in terms of side effects associated with tacrolimus treatment was also done.

\section{METHODS}

A prospective open parallel randomized study was carried out on 60 patients in the age group of 2-15 years at Regional Institute of Ophthalmology (M.D. Eye Hospital, Allahabad, Uttar Pradesh, India). The study was conducted during May 2014 to May 2015 on patients diagnosed as VKC. The written and informed consent from the patient/ parents/guardian and approval from Institutional Ethical Committee of MLN Medical College, Allahabad, Uttar Pradesh, India was taken.

\section{Inclusion criteria}

- Children of either sex having vernal keratoconjunctivitis with previous history of treatment with antiallergic drugs,

- Who were symptomatic,

- Parents/patient/guardian are able to follow study related advices,

- Parents/patient/guardian must be able to understand and give consent for study.

\section{Exclusion criteria}

- Patient less than 2 years of age,
- The patients with associated ocular disease for example uveitis, corneal degeneration or dystrophies or corneal opacity, strabismus, subluxated or dislocated lens and glaucoma,

- Patient with structural abnormalities (lid scarring, entropion),

- Presence of corneal infections and diseases,

- Patients with previous ocular surgery,

- Contact lens users,

- Using any other topical medication other than artificial tears,

- Using some other immunosuppressive systemic therapy or taking antibacterial treatment within 30 days of participating in study,

- Patients with presence of systemic disease other than co-existing allergic rhinitis, asthma and allergic rhinitis,

- Patients with reported hypersensitivity to FK- 506 or cyclosporine.

\section{Study protocol}

\section{Visit 1 (at week 0)}

Eligible candidates were enrolled into the study. Written informed consent was obtained. Patient underwent ophthalmic examination along with proper history of medications used earlier, family history of same illness, any other illness associated along with VKC and complete demographic characteristics at presentation including age, sex, age at onset of disease and duration of illness was taken. Patients were randomized into two groups. Patient in group A received $0.05 \%$ cyclosporine eye drops.

Patient's guardian or parents were instructed to instill it four times a day and not to use any other medication along with it. Patient in group B received 5 gm of tacrolimus $0.03 \%$ ophthalmic ointment. Patient's guardian or parents were instructed to apply ointment to conjunctival fornix every 12 hours and were also instructed to refrain from direct sunlight exposure soon after application of ointment. Patient slit lamp examination and external ocular photography was done. They were instructed to come after 2 weeks for follow up and to report any side effects or adverse event during the treatment immediately.

\section{Visit 2 (week 2) and visit 3 (week 4)}

For each patient, five major subjective symptoms scores and ocular sign scores of both eyes were again noted. Patients were asked about any possible side effects or adverse effects they have experienced on administration of drugs or during treatment. Patient slit lamp examination and external ocular photography was done.

\section{Visit 4 (week 8)}

Patient returned for final examination. Symptoms and sign scoring were done along with ocular photography. 


\section{Clinical scoring system}

Objective signs and subjective symptoms were observed at baseline (before treatment) and 2, 4, 6 and 8 weeks after treatment initiation. Five objective signs were assessed as shown in Table 1 (clinical evaluation criterion of allergic conjunctivitis) which included bulbar conjunctiva (hyperemia, oedema), palpebral conjunctiva (papillae), limbus (tantra's dot) and corneal involvement using 4 grades $(0=$ normal, $1=$ mild, $2=$ moderate, $3=$ severe $) .{ }^{11}$ In addition, each of five symptoms, including itching, discharge, tearing, photophobia and foreign body sensation was scored on a four-grade scale $0=$ none, 1 or mild (occasional symptoms), 2 or moderate (frequent symptoms), 3 or severe (constant symptoms). Scoring was done at baseline (therapy initiation) and at 2, 4, 6 and 8 weeks into treatment. In cases when therapy was discontinued, observations were not included for statistical evaluation.

Table 1: Grading scales for objective clinical signs.

\begin{tabular}{|c|c|c|}
\hline Signs & Score & Definition \\
\hline \multirow{4}{*}{$\begin{array}{l}\text { Palpebral } \\
\text { conjunctiva } \\
\text { Papillae }\end{array}$} & 3 & Size: $0.6 \mathrm{~mm}$ or more \\
\hline & 2 & Size: $0.3-0.5 \mathrm{~mm}$ \\
\hline & 1 & Size: $0.1-0.2 \mathrm{~mm}$ \\
\hline & 0 & None \\
\hline \multirow{4}{*}{$\begin{array}{l}\text { Bulbar } \\
\text { conjunctiva } \\
\text { Hyperemia }\end{array}$} & 3 & $\begin{array}{l}\text { Impossible to distinguish } \\
\text { individual blood vessels }\end{array}$ \\
\hline & 2 & Dilatation of many vessels \\
\hline & 1 & Dilatation of several vessels \\
\hline & 0 & None \\
\hline \multirow{4}{*}{ Oedema } & 3 & Bullous oedema \\
\hline & 2 & Thinner diffuse oedema \\
\hline & 1 & Localised oedema \\
\hline & 0 & None \\
\hline \multirow{4}{*}{$\begin{array}{l}\text { Limbus } \\
\text { Tantra's dot }\end{array}$} & 3 & 9 or more \\
\hline & 2 & $5-8$ dots \\
\hline & 1 & $1-4$ dots \\
\hline & 0 & None \\
\hline \multirow{4}{*}{$\begin{array}{l}\text { Corneal } \\
\text { epithelial } \\
\text { signs }\end{array}$} & 3 & Shield ulcer or corneal erosion \\
\hline & 2 & $\begin{array}{l}\text { Exfoliation superficial } \\
\text { punctate keratitis }\end{array}$ \\
\hline & 1 & Superficial punctate keratitis \\
\hline & 0 & None \\
\hline
\end{tabular}

Demographic variables collected and examined. The primary outcome was the change in total signs and symptom scores from baseline. The severity of total subjective symptoms (TSSS) and objective ocular signs (TOSS) at each visit were summed. Maximal values of TSSS and TOSS were 15. These scores were used for comparison within and between groups.

Data were summarized as Mean \pm SE (standard error of the mean). Groups were compared by independent Student's t test. Groups were also compared by repeated measures analysis of variance (ANOVA) using general linear models
(GLM) and the significance of mean difference within (intra) and between (inter) the groups was done by Tukey's post hoc test. Discrete (categorical) groups were compared by chi-square $\left(\chi^{2}\right)$ test. A two-tailed $\mathrm{p}$ value less than 0.05 $(\mathrm{p}<0.05)$ was considered statistically significant. All analyses were performed on SPSS software (windows version 17.0).

\section{RESULTS}

Out of 60 patients enrolled, 17 patients did not appear for participation in this study and were excluded from study. Total 43 patients (cyclosporine $=21$ and tacrolimus=22) were found evaluable in the present study. Total subjective symptoms scores (TSSS) and total ocular sign scores (TOSS) of both eyes were subjected for statistical analysis.

Comparing the mean age of two groups, t-test revealed similar age between the two groups $(7.57 \pm 0.42$ vs $8.00 \pm 0.81, \mathrm{t}=0.46, \mathrm{p}=0.645)$ i.e. not differed statistically. Further, in both groups, the frequency (\%) of males was higher than females with slightly higher being in tacrolimus group $(63.6 \%)$ than cyclosporine group $(52.4 \%)$.

Similarly, the mean age at onset of disease $(5.95 \pm 0.44$ vs $6.18 \pm 0.68, \mathrm{t}=0.28, \mathrm{p}=0.780)$ and duration of illness $(1.71 \pm 0.17$ vs. $1.85 \pm 0.20, \mathrm{t}=0.53, \mathrm{p}=0.599)$ also not differed between the two groups. In other words, the subjects of two groups were demographically matched and comparable thus, may also not influence the study outcome measures (TSSS and TOSS).

\section{Outcome measures}

\section{Total subjective symptom score (TSSS)}

The pre ( 0 week) and post (2, 4, 6 and 8 weeks) treatment total subjective symptom scores (TSSS) of two groups are summarized Table 2 . The mean TSSS in both groups decreased (improved) after the treatment and the decrease (improvement) was evident higher in tacrolimus group than cyclosporine group. Evaluating the effect of groups and periods on TSSS, ANOVA revealed insignificant effect of groups $(\mathrm{F}=2.23, \mathrm{p}=0.143)$ while significant effect of periods ( $\mathrm{F}=210.41, \mathrm{p}<0.001)$ on TSSS. However, the interaction (groups $\mathrm{x}$ periods) effect of both on TSSS was found insignificant $(\mathrm{F}=0.77, \mathrm{p}=0.547)$.

Further, for each group, comparing the mean TSSS among the periods Table 3, Tukey test showed significant ( $p$ $<0.001$ ) decrease (improvement) in TSSS at all post periods (2, 4, 6 and 8 weeks) as compared to pre-treatment (0 week) of both groups. Furthermore, in both groups, it also decreases significantly ( $\mathrm{p}<0.05$ or $\mathrm{p}<0.01$ or $\mathrm{p}$ $<0.001$ ) at all post periods as compared to respective predecessor periods except 4 weeks to 6 weeks in cyclosporine group and 6 weeks to 8 weeks in tacrolimus group. Similarly, for each period, comparing the mean TSSS between the groups Table 4, Tuk ey test showed 
similar ( $p>0.05$ ) TSSS between the groups at all periods i.e. not differed statistically though at final evaluation (mean change from baseline to 8 weeks), it improved $5.2 \%$ more in tacrolimus group $(83.7 \%)$ than cyclosporine group $(78.5 \%)$.

Table 2: Pre and post total subjective symptom scores $($ Mean \pm SE) of two groups.

\begin{tabular}{|lll|}
\hline Periods & Cyclosporine $(\mathbf{n = 2 1})$ & Tacrolimus $(\mathbf{n = 2 2})$ \\
\hline 0 week & $18.57 \pm 1.32$ & $16.68 \pm 0.98$ \\
\hline 2 weeks & $12.86 \pm 1.06$ & $11.77 \pm 0.71$ \\
\hline 4 weeks & $7.71 \pm 0.73$ & $7.27 \pm 0.65$ \\
\hline 6 weeks & $6.57 \pm 0.50$ & $4.36 \pm 0.74$ \\
\hline 8 weeks & $4.00 \pm 0.62$ & $2.73 \pm 0.60$ \\
\hline
\end{tabular}

Table 3: For each group, comparison (p value) of mean total subjective symptom scores within the groups by Tukey post hoc test.

\begin{tabular}{|lll|}
\hline Comparison (periods) & Cyclosporine & Tacrolimus \\
\hline 0 week vs 2 weeks & $<0.001$ & $<0.001$ \\
\hline 0 week vs 4 weeks & $<0.001$ & $<0.001$ \\
\hline 0 week vs 6 weeks & $<0.001$ & $<0.001$ \\
\hline 0 week vs 8 weeks & $<0.001$ & $<0.001$ \\
\hline 2 weeks vs 4 weeks & $<0.001$ & $<0.001$ \\
\hline 2 weeks vs 6 weeks & $<0.001$ & $<0.001$ \\
\hline 2 weeks vs 8 weeks & $<0.001$ & $<0.001$ \\
\hline 4 weeks vs 6 weeks & 0.919 & 0.008 \\
\hline 4 weeks vs 8 weeks & $<0.001$ & $<0.001$ \\
\hline 6 weeks vs 8 weeks & 0.043 & 0.512 \\
\hline
\end{tabular}

Table 4: For each period, comparison (p value) of mean total subjective symptom scores between the groups by Tukey post hoc test.

\begin{tabular}{|ll|}
\hline Periods & Comparison (cyclosporine vs tacrolimus) \\
\hline 0 week & 0.833 \\
\hline 2 weeks & 0.995 \\
\hline 4 weeks & 1.000 \\
\hline 6 weeks & 0.671 \\
\hline 8 weeks & 0.984 \\
\hline
\end{tabular}

\section{Total ocular sign score (TOSS)}

The pre ( 0 week) and post (2, 4, 6 and 8 weeks) treatment total ocular sign scores (TOSS) of two groups are summarized in Table 5. It showed that the mean TOSS in both groups decreased (improved) after the treatment and the decrease (improvement) was evident higher in tacrolimus group than cyclosporine group. Evaluating the effect of groups and periods on TOSS, ANOVA revealed insignificant effect of groups $(\mathrm{F}=3.58, \mathrm{p}=0.065)$ while significant effect of periods $(\mathrm{F}=152.72, \mathrm{p}<0.001)$ on TOSS. However, the interaction (groups $\mathrm{x}$ periods) effect of both on TOSS was found to be insignificant $(\mathrm{F}=1.02$, $\mathrm{p}=0.398$ ).
Table 5: Pre and post total ocular sign scores (Mean \pm SE) of two groups.

\begin{tabular}{|lll|}
\hline Periods & Cyclosporine $(\mathbf{n}=\mathbf{2 1})$ & Tacrolimus $(\mathbf{n = 2 2})$ \\
\hline 0 week & $8.57 \pm 0.87$ & $6.91 \pm 0.35$ \\
\hline 2 weeks & $6.86 \pm 0.61$ & $5.73 \pm 0.45$ \\
\hline 4 weeks & $4.00 \pm 0.48$ & $3.45 \pm 0.41$ \\
\hline 6 weeks & $3.24 \pm 0.54$ & $2.00 \pm 0.28$ \\
\hline 8 weeks & $2.57 \pm 0.50$ & $1.27 \pm 0.38$ \\
\hline
\end{tabular}

Further, for each group, comparing the mean TOSS among the periods Table 6 , Tukey test showed significant ( $p<0.01$ or $\mathrm{p}<0.001$ ) decrease (improvement) in TOSS at all post periods (2, 4, 6 and 8 weeks) as compared to pre-treatment (0 week) of both groups except 0 week to 2 weeks in tacrolimus group.

Furthermore, in both groups, it also decrease significantly ( $\mathrm{p}<0.05$ or $\mathrm{p}<0.01$ or $\mathrm{p}<0.001$ ) at all post periods as compared to respective predecessor periods except 4 weeks to 6 weeks, and 6 weeks to 8 weeks in cyclosporine group and 6 weeks to 8 weeks in tacrolimus group. Similarly, for each period, comparing the mean TOSS between the groups Table 7, Tukey test showed similar ( $p$ $>0.05$ ) TOSS between the groups at all periods i.e. not differed statistically though at final evaluation (mean change from baseline to 8 weeks), it improved $11.6 \%$ more in tacrolimus group (81.6\%) than cyclosporine group (70.0\%).

Table 6: For each group, comparison (p value) of mean total ocular sign scores within the groups by Tukey post hoc test.

\begin{tabular}{|ll|l|}
\hline Comparison (periods) & Cyclosporine & Tacrolimus \\
\hline 0 week vs 2 weeks & 0.001 & 0.083 \\
\hline 0 week vs 4 weeks & $<0.001$ & $<0.001$ \\
\hline 0 week vs 6 weeks & $<0.001$ & $<0.001$ \\
\hline 0 week vs 8 weeks & $<0.001$ & $<0.001$ \\
\hline 2 weeks vs 4 weeks & $<0.001$ & $<0.001$ \\
\hline 2 weeks vs 6 weeks & $<0.001$ & $<0.001$ \\
\hline 2 weeks vs 8 weeks & $<0.001$ & $<0.001$ \\
\hline 4 weeks vs 6 weeks & 0.682 & 0.009 \\
\hline 4 weeks vs 8 weeks & 0.015 & $<0.001$ \\
\hline 6 weeks vs 8 weeks & 0.825 & 0.711 \\
\hline
\end{tabular}

Table 7: For each period, comparison (p value) of mean total ocular sign scores between the groups by Tukey post hoc test.

\begin{tabular}{|ll|}
\hline Periods & Comparison (cyclosporine vs tacrolimus) \\
\hline 0 week & 0.390 \\
\hline 2 weeks & 0.855 \\
\hline 4 weeks & 0.999 \\
\hline 6 weeks & 0.776 \\
\hline 8 weeks & 0.725 \\
\hline
\end{tabular}




\section{Side effects}

No serious adverse effect was reported during the study. The most frequent treatment related ocular adverse event in tacrolimus was mild ocular irritation in $9.09 \%$ cases $(2 / 22)$ while the most frequent adverse effect in cyclosporine group was burning sensation on instillation of eye drops. It was reported in $80.95 \%$ cases $(17 / 21)$. Second adverse effect reported in cyclosporine group was redness in eyes, found in $19.04 \%$ cases (4/21). No ocular infection was reported during the treatment period.

\section{DISCUSSION}

In this study both tacrolimus $0.03 \%$ ophthalmic ointment and cyclosporine $0.05 \%$ eye drops were found to be effective for treatment of VKC. Authors did not include a placebo group or control group in the study since it seemed unethical to leave patients with symptomatic VKC untreated for such a prolonged period of 8 weeks.

Age at presentation is almost same for this study and other studies. VKC is more common in younger age group and occurrence decrease with increase in age due to desensitization of receptors responsible for allergic reactions and decreased production of other pathological mediators.

Frequency of males was higher than females in both the groups, 11 males $(52.4 \%)$ and 10 females $(47.6 \%)$ in cyclosporine group and 14 males $(63.6 \%)$ and 8 females $(36.4 \%)$ in tacrolimus group. In total 25 males and 18 females presenting with VKC were enrolled in this study. Other studies also show $\mathrm{VKC}$ is more common in males than females. ${ }^{12}$

\section{Medications}

About $0.03 \%$ tacrolimus ophthalmic ointment and $0.05 \%$ cyclosporine eye drops were used for the study purpose. Tacrolimus dermal ointments are easily available in market but only ophthalmic ointment available in the setup after extensive search was $0.03 \%$ formulation. Cyclosporine eye drops were available in $0.05 \%$ and $0.1 \%$ concentration and $0.05 \%$ formulation was more easily available. Studies justify use of these concentration in treatment of vernal keratoconjunctivitis. In Vichyanond $\mathrm{P}$ et al, study $0.1 \%$ tacrolimus eye ointment and $2 \%$ cyclosporine eye drops were used. ${ }^{13}$

Tacrolimus is a hydrophobic molecule which mean its aqueous solution at clinically useful concentrations are likely to be unstable. Attempts to overcome this problem were done by preparing ophthalmic solutions in castor oil, olive oil and dextrin. However, burning, redness, itching and epithelial keratitis limits the use of such oil vehicles. Dermal ointments were used for some studies. Muller GG et al, used $0.03 \%$ tacrolimus dermal ointment protopic directly to conjunctival fornix and according to them there is sufficient reports in literature of its good tolerance and low toxic effects on ocular surface. ${ }^{14}$ Pucci $\mathrm{N}$ et al, conducted studies using cyclosporine $1 \%$ and $2 \%$ concentrations 15 in other study in 2015 they used $0.1 \%$ concentrations for patients who failed to respond to $1 \%$ Cyc eye drops. ${ }^{16}$ Akpek EK et al, used $0.05 \%$ cyclosporine eye drops for treatment of severe steroid resistant vernal keratoconjunctivitis. ${ }^{10}$

\section{Outcome measures}

Total subjective symptom score (TSSS) at final evaluation (mean change from baseline to 8 weeks), improvement is $5.2 \%$ more in tacrolimus group (83.7\%) than cyclosporine group $(78.5 \%)$. Only study that compares tacrolimus ointment and cyclosporine eye drops in treatment of VKC by Vichyanond $\mathrm{P}$ et al, there is also reduction of TSSS within group (compared to their baselines) and became statistically significant at week 4 for FK-506 ( $p<0.01)$ and for cyclosporine $(\mathrm{p}<0.01)$. Such reductions were maintained in both groups throughout the 8-week period. Total improvement of TSSS (as a percentage of baselines) among FK 506 was $86.49 \%$ and cyclosporine was $79.04 \%$.

Total ocular sign scores (TOSS) final evaluation (mean change from baseline to 8 weeks), improvement is $11.6 \%$ more in tacrolimus group $(81.6 \%)$ than cyclosporine group (70.0\%). In Vichyanond $\mathrm{P}$ et al, found despite a reduction of TOSS within the cyclosporine group, no significant change was observed compared to baseline $(p>0.05)$.

In this study concentration of two drugs used was $0.03 \%$ for tacrolimus ointment and $0.05 \%$ for cyclosporine eye drop while in Vichyanond P et al, study it was $0.1 \%$ for tacrolimus ointment and $2 \%$ for cyclosporine eye drops. Second difference was demographic variability as this study was carried out in Bangkok, Thailand and this study in north India. Moreover, Vichyanond P et al, does not use standard preparation of drugs their study medications were formulated by a hospital pharmacist. ${ }^{13}$

\section{Side effects}

For the assessment of safety evaluation of visual acuity, IOP, pupil diameter and other clinical findings were taken into consideration. No serious adverse effect was reported during the study. The only treatment related ocular adverse event in tacrolimus was mild ocular irritation. Most frequent side effect seen with cyclosporine treatment is burning sensation soon after instillation of eye drops and is reported in almost all studies done. Tacrolimus is associated with transient ocular irritation only. Study conducted by Gupta et al, mentions occurrence of fungal infections with use of cyclosporine ophthalmic preparation. ${ }^{17}$ No such events were reported in any other studies or in this study.

Tacrolimus ophthalmic preparation appears to be safe drug as there are no reports of any serious side effects associated with its use from earlier studies and even from this study. Although safety would have been better commented if 
blood analysis for finding out any systemic absorption of drugs has been carried out. Ebihara $\mathrm{N}$ et al, found that topical tacrolimus led to minimal systemic absorption of the compound. ${ }^{18}$

\section{CONCLUSION}

Cost of treatment with tacrolimus is minimal in comparison to that of cyclosporine.

The study found tacrolimus is a better drug for treatment of vernal keratoconjunctivitis than cyclosporine although findings of present study may need further validation on larger sample size.

The major limitation of this study is small sample size and lack of blinding or placebo group as a result there are chances of subjecting to statistical error. Larger sample size and multicentric studies need to be conducted in Indian setup to confirm or add to these findings.

Authors have not taken recurrence of disease after discontinuation of medications into consideration the reason been limited and short time of this study. Primary outcomes in terms of efficacy and side effects should be find out conducting long term studies, using different concentration of tacrolimus and taking recurrence of disease after discontinuing medication into consideration as recurrence is major problem in present treatment options of VKC.

\section{ACKNOWLEDGEMENTS}

Authors would like to thank statistician and residents of ophthalmology department for thier support during study.

Funding: No funding sources

Conflict of interest: None declared

Ethical approval: The study was approved by the Institutional Ethics Committee of MLN Medical College, Allahabad, Uttar Pradesh, India

\section{REFERENCES}

1. Bielory L. Allergic and immunologic disorder of the eye. Part II: Ocular allergy. J Allergy Clin Immunol. 2000;106:1019-32.

2. Leonardi A. Vernal keratoconjunctivitis: pathogenesis and treatment. Prog Retin Eye Res. 2002;21:319-39.

3. Bonini S. Atopic keratoconjunctivitis. Allergy. 2004;59:(78):71-3.

4. Cook EB. Tear cytokines in acute and chronic ocular allergic inflammation. Curr Opin Allergy Clin Immunol. 2004;4:441-5.

5. Ohashi Y, Ebihara N, Fujishima H. A randomized, placebo-controlled clinical trial of tacrolimus ophthalmic suspension $0.1 \%$ in severe allergic conjunctivitis. J Ocul Pharmacol Ther. 2010;26:16573.

6. Tabbara KF. Ocular complications of vernal keratoconjuctivitis. Can J Ophthalmol. 1999;34:8892.

7. Ang M, Ti SE, Loh R. Steroid-induced ocular hypertension in Asian children with severe vernal keratoconjunctivitis. Clin Ophthalmol. 2012;6:12538.

8. Ohji M, Kinoshita S, Ohmi E. Marked intraocular pressure response to instillation of corticosteroids in children. Am J Ophthalmol. 1991;112:450-4.

9. Tomida I, Schlote T, Bräuning J, Heide PE, Zierhut M. Cyclosporin A 2\% eyedrops in therapy of atopic and vernal keratoconjunctivitis. Ophthalmol. 2002;99(10):761-7.

10. Akpek EK, Dart JK. A randomized trial of topical cyclosporin $0.05 \%$ in topical steroid-resistant atopic keratoconjunctivitis. Ophthalmol. 2004;111(3):47682.

11. Takamura E, Uchio E, Ebihara N, Ohno S, Ohahsi Y. Japanese guidelines for allergic conjunctival diseases. Allergol Int. 2011;60(2):191-203.

12. Bonini S. Vernal keratoconjunctivitis revisited: a case series of 195 patients with long-term follow up. Ophthalmol. 2000;107(6):1157-63.

13. Vichyanond P. A double-masked comparison of $0.1 \%$ tacrolimus ointment and $2 \%$ cyclosporine eye drops in the treatment of vernal keratoconjunctivitis in children. Asian Pac J Allergy Immunol. 2012;30:17784.

14. Müller GG, José NK, Castro RS. Topical tacrolimus $0.03 \%$ as sole therapy in vernal keratoconjunctivitis. Eye Contact Lens. 2014;40(2):79-83.

15. Pucci N, Caputo R. Long-term safety and efficacy of topical cyclosporine in 156 children with vernal keratoconjunctivitis. Int J Immunopathol Pharmacol. 2010;23(3):865-71.

16. Pucci N, Caputo R. Tacrolimus vs cyclosporine eyedrops in severe cyclosporine-resistant vernal keratoconjunctivitis: a randomized, comparative, double-blind, crossover study. Pediatr Allergy Immunol. 2015;26(3):256-61.

17. Gupta V, Sahu PK. Topical cyclosporin A in the management of vernal keratoconjunctivitis. Eye (London, England). 2001 Feb;15(Pt 1):39-41.

18. Ebihara N, Ohashi Y, Fujishima H, Fukushima A, Nakagawa Y. Blood level of tacrolimus in patients with severe allergic conjunctivitis treated by $0.1 \%$ tacrolimus ophthalmic suspension. Allergol Int. 2012;61:275-82.

Cite this article as: Choudhary $\mathrm{P}$, Singh SP, Chaurasia RC, Jindal M. A prospective study to compare the efficacy of tacrolimus vs cyclosporine in vernal keratoconjunctivitis in children in India. Int $\mathbf{J}$ Basic Clin Pharmacol 2019;8:1297-302. 